\title{
DNA topoisomerase I and II expression in drug resistant germ cell tumours
}

\section{DM Berney*,', J Shamash², J Gaffney', S Jordan' and RTD Oliver²}

'Department of Histopathology and Morbid Anatomy, St Bartholomew's Hospital, Queen Many's School of Medicine and Dentistry, London ECI 7BE, UK;

${ }^{2}$ Department of Medical Oncology, St Bartholomew's Hospital, Queen Mary's School of Medicine and Dentistry, London ECI 7BE, UK

A small number of testicular germ cell tumours are refractory to current chemotherapy regimens. DNA topoisomerase I is the target for several new drugs and a potential candidate treatment for chemorefractory germ cell tumours. DNA topoisomerase $\| \alpha$ is the target for etoposide, which is currently used regularly in germ cell tumour treatment. The expression of DNA topoisomerase I and Il $\alpha$ were therefore assessed immunohistochemically in a range of testicular tumours, especially those with persistent malignant elements on retroperitoneal lymph node dissection. Pre-chemotherapy orchidectomy specimens were matched with postchemotherapy retroperitoneal lymph node dissections to examine changes in expression. There was considerable variation in the expression of topoisomerase I in different tumour types. Both yolk sac tumours and teratoma, mature showed universal expression of topoisomerase I, while $38 \%$ of seminomas and 30\% of embryonal carcinomas were positive. Strong topoisomerase $\| \alpha$ expression was found in embryonal carcinoma. There was a negative correlation between topoisomerase I and Il $\alpha$ expression $(P=0.004)$ and downregulation of topoisomerase $\| \alpha$ after chemotherapy $(P=0.02)$. Topoisomerase I expression appears to increase in those cases with residual teratoma, mature, but is largely unchanged in those cases remaining as embryonal carcinoma. These results suggest that topoisomerase I inhibitors may be useful in chemorefractory germ cell tumours, especially yolk sac tumours and where there are unresectable residual teratoma, mature deposits.

British Journal of Cancer (2002) 87, 624 -629. doi: 10.1038/sj.bjc.6600472 www.bjcancer.com

(C) 2002 Cancer Research UK

Keywords: topoisomerase; germ cell tumour; testis; embryonal carcinoma; seminoma; Ki-67

The treatment of metastatic non-seminomatous germ cell tumours consists of orchidectomy plus 'BEP' combination chemotherapy bleomycin, etoposide and cisplatin. First line chemotherapy gives a 5 -year survival rate for patients with metastatic germ cell tumours (GCT) of over 80\% (International Germ Cell Cancer Collaborative Group, 1997). Despite the high success rate of this treatment, the $\mathrm{BEP}$ regimen has serious side effects and there is a $1 \%$ incidence of drug fatality. Residual masses may remain and it has become common practise to excise these surgically (Einhorn et al, 1981). Histology from these masses has a complex range of appearances and the complete resection of embryonal carcinoma (EC) or other malignant elements is important (Fox et al, 1993; Fizazi et al, 1999; Albers et al, 2000). Residual teratoma, mature (TM) is also resected where possible because of the danger of dedifferentiation, or transformation to a variety of other tumour types (Hull et al, 1994; Little et al, 1994; Michael et al, 2000).

Controversy exists regarding the use of further adjuvant chemotherapy (salvage chemotherapy) in these patients, as most are cured by surgery alone (Tait et al, 1984; Williams et al, 1997). It is clear however that effective salvage chemotherapy does exist for those patients who do relapse (Loehrer et al, 1998; Shamash et al, 1999). The omission of chemotherapy in these patients would be considered as undertreatment. Patients whose germ cell tumours recur at greater than 2 years from original resec-

\footnotetext{
*Correspondence: DM Berney;

E-mail: D.Berney@bartsandthelondon.nhs.uk

Received 18 January 2002; revised 21 May 2002; accepted 23 May 2002
}

tion (late recurrences) have a generally poor chemo-responsiveness to current therapies (Michael et al, 2000). There remains therefore, a small subgroup of patients who are resistant to current modes of therapy.

The human DNA topoisomerases are members of the gyrase family of enzymes. They are nuclear enzymes, which transiently break and unwind DNA at times when the cell requires access to the genetic material for replication and transcription (Wang, 1996). They are also involved in many cellular activities including chromosome condensation and recombination, DNA repair and segregation during mitosis (Husain et al, 1994).

Genes coding for the topoisomerase (topo) enzymes are highly conserved across species. Topo I is targeted by the camptothecins (Takimoto et al, 1998) and has been shown to be elevated in many human malignancies (Husain et al, 1994; Mcleod et al, 1994). Topo II isoenzymes are the targets for the epipodophyllotoxins and for DNA intercalators such as the anthracyclines (Sano and Shuhin, 1995).

Typically, these drugs do not inhibit the free enzyme but stabilise the covalently bound topoisomerase-DNA complex (Rubin, 2000), thus preventing the rejoining of the broken DNA fragments. They act not so much as inhibitors, but as 'poisons'. The sensitivity of cells to the topoisomerase-targeted drugs is therefore related to the levels of topoisomerase in the nucleus, making immunohistochemical assessment a putative measure of likely cell sensitivity to chemotherapy (Madden and Champoux, 1992). The camptothecins have been investigated recently as possible agents for testicular GCT's (Sano and Shuhin, 1995; Miki et al, 1997; Coleman et al, 2000). 
The aims of this project are to identify the presence of the topo I and II $\alpha$ in different testicular tumour types, especially those resistant to current therapeutic regimens, to aid the identification of potential targets for salvage chemotherapy using the topoisomerase inhibitors.

\section{MATERIALS AND METHODS}

Cases were identified from the Barts and The London NHS Trust medical oncology database. These included 14 matched cases of orchidectomy plus retroperitoneal lymph node dissection from patients who had residual tumour following their initial course of therapy. Some of the matched pre-chemotherapy orchidectomy tumour blocks were requested from other hospitals, which were largely those participating in the East Anglia germ cell tumour group. Thirteen cases were also identified of retroperitoneal lymph node dissection following an initial course of therapy but where the original orchidectomy was not available. Nearly all these cases had residual malignant or immature elements and therefore represented a selection of the cases which had not responded to conventional therapy. Twelve orchidectomies were also identified from patients who had been diagnosed with seminomas for comparison with the teratoma group. All cases were anonymised.

The cases were all reviewed and the different elements within them identified assisted by immunochemistry where appropriate. Embryonal carcinoma was identified by the immunohistochemical presence of CD30 in the primary tumours, or by histological appearances in the post-chemotherapy cases (Berney et al, 2001a). $3 \mu \mathrm{m}$ formalin fixed, paraffin embedded tissue sections were cut from the selected tissue blocks. Antigen retrieval was used for all of the antibodies used. The antibodies used were topo I (mouse monoclonal antibody Clone ID6, Novacastra), topo II $\alpha$ (mouse monoclonal antibody Code 3F6, Novacastra), topo II $\alpha$ (rabbit polyclonal antibody, Novacastra) and Ki-67 (rabbit polyclonal Code AO47, Dako). Ki-67 was included to compare the proliferation index with the topo II enzymes. Normal tonsil was used for a positive control and a negative control was included for each case.

Protocols for immunochemistry were followed according to those used for the topoisomerases in previous studies (Monnin et al, 1999). All the antibodies used show nuclear staining. Cytoplasmic staining was disregarded. Protocols for immunohistochemical detection of topo I followed a previous study (Holden et al, 1997) and graded the expression of the enzyme in the tissue samples on a subjective scale of 0 to $3+$. Staining $2+$ or $3+$ was counted as positive, and anything less as negative. The expression of the topo II enzyme and Ki-67 was assessed by quantitatively calculating the number of positive cells out of 500 (expressed as a percentage). Fifty cells were counted in 10 random fields within the tumour area. Five hundred cells were counted within each case.

\section{RESULTS}

The expression of topo I in the different tumour types is represented in Table 1. Tonsillar tissue, used as a positive control, showed strong staining in lymphoid follicles and in squamous epithelium. Macrophages, which are seen in all normal follicles ingesting apoptotic debris, were noted to be negative (Figure 1). Background fibrous tissue was also negative for all the tested antibodies. Positive internal controls included lymphocytes especially in the seminomas. Negative internal controls were areas of normal spermatogenesis in the testes where the spermatids, as expected, were seen to be negative (Figure 2).

Universal strong expression was shown in TM (Figure 3) and also in yolk sac (Figure 4). Pre chemotherapy, both EC and seminoma showed similar percentages of cases to be positive (five out of 12 and five out of 13 respectively). After chemotherapy however, only two out of 11 cases of EC showed nuclear positivity. Prominent cytoplasmic staining was noted in the EC group in many cases but this was not counted as positive. Seminomas were chosen as the control group to attempt to determine statistically which of the groups of tumour may respond well to anti-topo I therapy. TM was universally positive for topo I and is significantly different from the seminoma group $(P<0.003$, Fisher's exact test). Yolk sac (YS) was also significantly different from seminoma $(P<0.018)$. The changes in expression of topo I after chemotherapy showed that both increases and decreases in expression occurred. Increases occurred in cases which differentiated from EC to TM or YS. Cases with persistent EC either became negative or remained unchanged.

Twenty-eight of the total number of specimens were stained with both the polyclonal and monoclonal version of the topo II $\alpha$ antibody. The tonsil used for control purposes showed very strong nuclear staining in follicles and in basal epithelium. Similar to topo I, spermatids were negative where present in primary orchidectomy cases. The correlation between both antibodies against topo II was strong $(R=0.908 ; P<0.001)$ after testing 28 of the cases and therefore the remaining cases were tested with the monoclonal antibody only. The frequency distribution of this

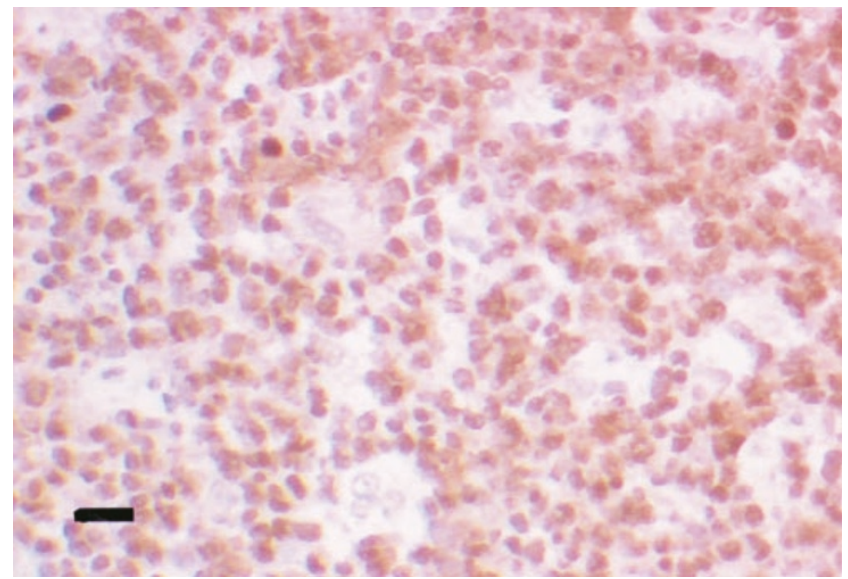

Figure I Control showing strong positivity for topo I in a lymphoid follicle. Note the negative macrophages with larger irregular nuclei. Black bar $=50 \mu \mathrm{m}$.

Table I Topoisomerase I and II $\boldsymbol{\alpha}$ positivity in selected tumour types

\begin{tabular}{lccccc}
\hline & $\begin{array}{c}\text { Primary } \\
\text { seminoma }\end{array}$ & $\begin{array}{c}\text { Primary } \\
\text { EC }\end{array}$ & $\begin{array}{c}\text { Post- } \\
\text { chemotherapy EC }\end{array}$ & $\begin{array}{c}\text { Yolk } \\
\text { sac }\end{array}$ & $\begin{array}{c}\text { Post } \\
\text { chemotherapy TM }\end{array}$ \\
\hline $\begin{array}{l}\text { Topo I } \\
\text { Positive }\end{array}$ & 5 & 5 & 2 & 6 & 10 \\
$\quad$ Negative & 8 & 7 & 9 & 0 & 0 \\
$\begin{array}{l}\text { Topo II } \\
\text { Positive }\end{array}$ & 6 & 8 & 5 & 1 & 0 \\
Negative & 7 & 4 & 6 & 5 & 10 \\
\hline
\end{tabular}

$\mathrm{EC}=$ Embryonal carcinoma, $\mathrm{TM}=$ Teratoma, mature. 


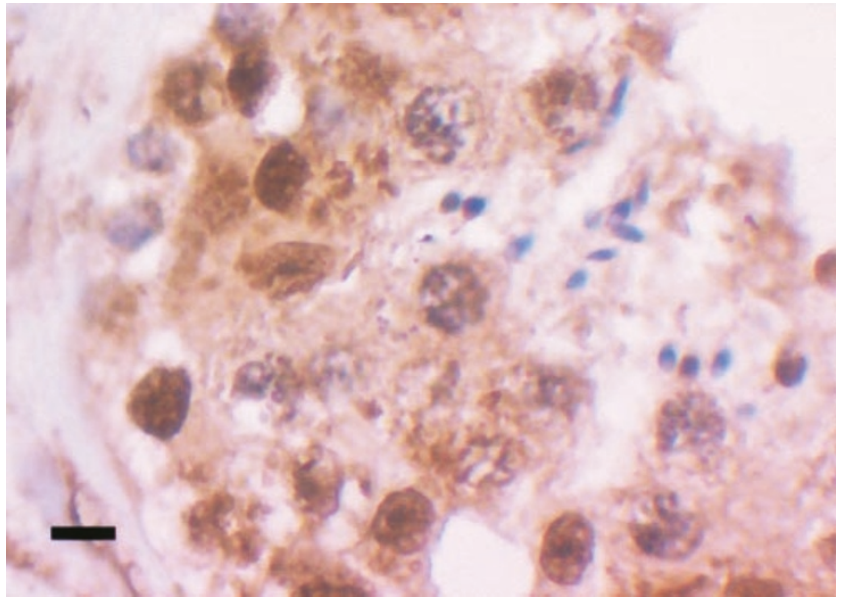

Figure 2 Cross-section of a normal seminiferous tubule showing strongly topo I positive spermatocytes and negative spermatids. Black bar $=15 \mu \mathrm{m}$

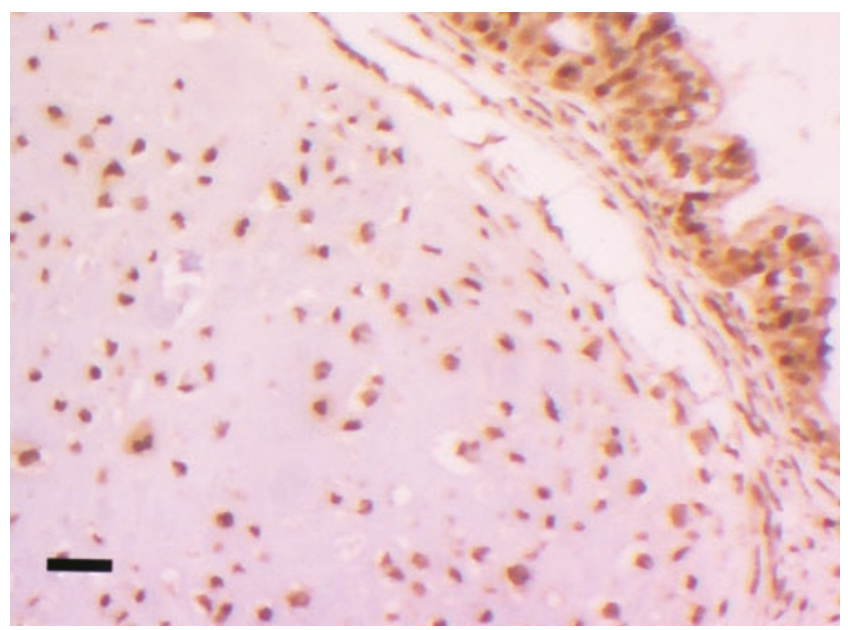

Figure 3 Strong topo I positivity in a mature teratoma after chemotherapy, showing positive chondrocytes and glandular epithelium (top right). Black bar $=50 \mu \mathrm{m}$.

antibody was bimodal with $24 \%$ used as the cut off between positive and negative cases (Figure 5). Topo II positivity is compared with the tumour type in Table 1. The highest topo II index was seen in cases of EC. Lower rates were seen in seminomas (Figure 6 ), YS and TM. The TM group showed a significantly lower topo II $\alpha$ index than seminoma ( $P=0.019$, Fisher's exact test $)$. Topo I was also compared with topo II expression (Table 2). There was a strong inverse correlation between the two proteins $(P=0.004$, Fisher's exact test), however a few tumours showed dual high expression. Ki-67 showed a positive correlation ( $r=0.69$, $P<0.01$ ) with topo II expression (Figure 7), demonstrating that topo II $\alpha$ expression is a reasonable measure of proliferating cells. This has been reported in many previous studies (Davidson et al, 2000; Gupta et al, 2000; Morisaki et al, 2000). There was a significant reduction $(P=0.02$, Wilcoxan signed ranks matched pairs test) in topo II positivity after chemotherapy (Figure 8). It was noted that the pre-treatment samples were normally distributed $(P=0.188$, Anderson-Darling test $)$ while the post treatment samples were not normally distributed $(P<0.001$, AndersonDarling test).

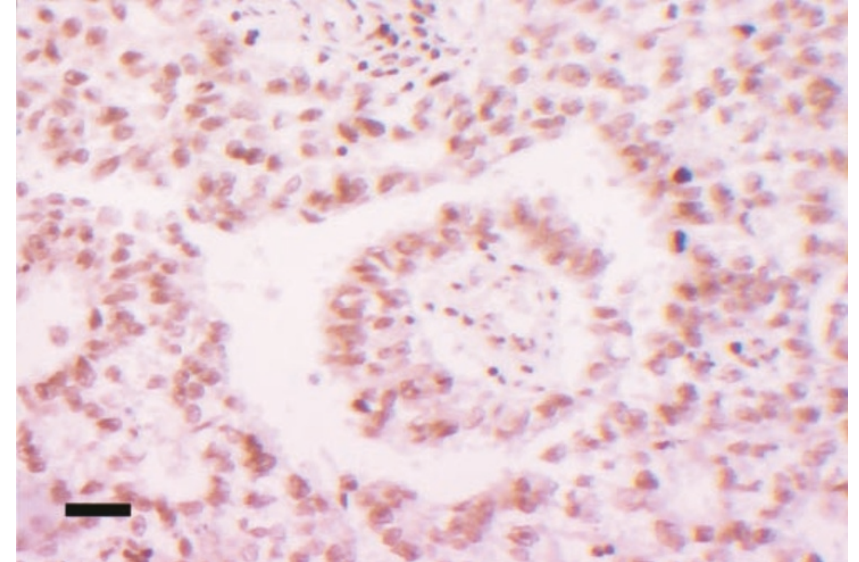

Figure 4 Topo I positivity in a yolk sac tumour. Black bar=50 $\mu \mathrm{m}$.

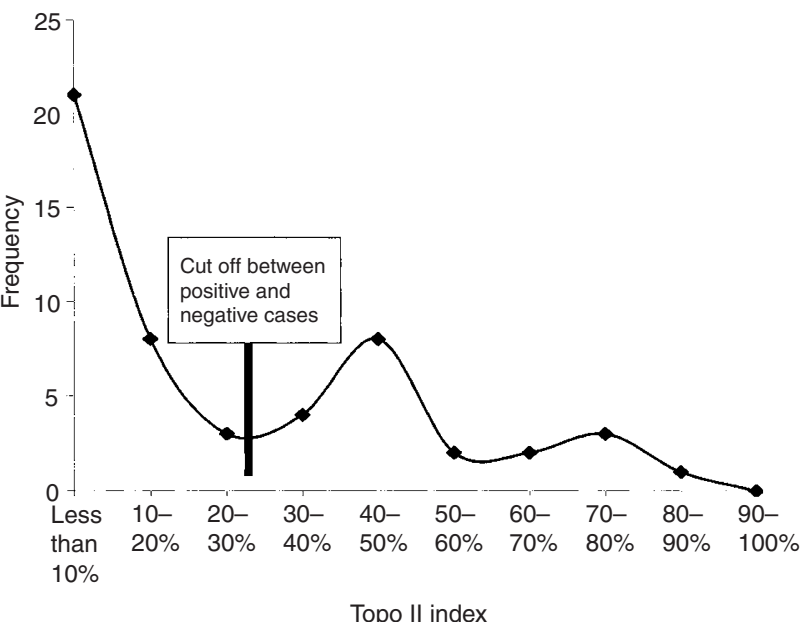

Figure 5 Frequency distribution of topoisomerase Il $\alpha$ index.

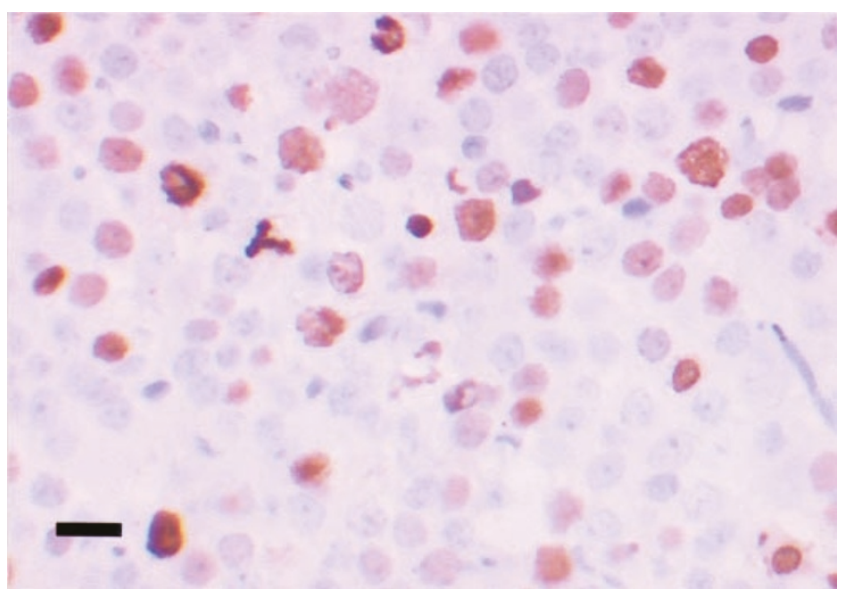

Figure 6 Positive nuclear staining for topo II in a seminoma. Note the strongly positive tripolar mitosis. Black bar $=30 \mu \mathrm{m}$.

\section{DISCUSSION}

DNA Topoisomerase I has been identified as a molecular target for the plant alkaloid Camptothecin (Husain et al, 1994; Holden et al, 1997). This is a derivative of Camptotheca acuminata 
Table 2 Comparison of topoisomerase I and II

\begin{tabular}{lcc}
\hline & Topoisomerase I| & Topoisomerase I| \\
& Positive & Negative \\
Topoisomerase I Positive & 6 & 23 \\
Topoisomerase | Negative & 15 & 9 \\
\hline
\end{tabular}

There is a negative correlation between topo I and II ( $P=0.004$, Fisher's exact test).

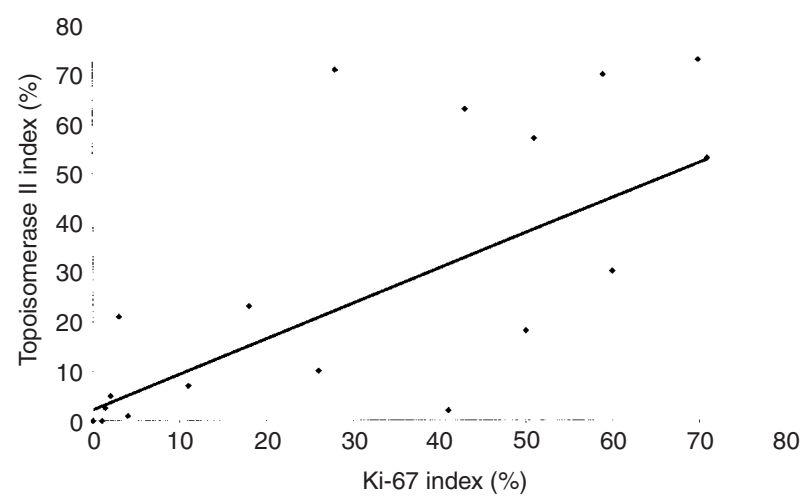

Figure 7 Comparison of the percentage of Ki-67 positive cells with the percentage of topoisomerase $\| \alpha$ positive cells $(r=0.69, P<0.0 \mathrm{I})$.

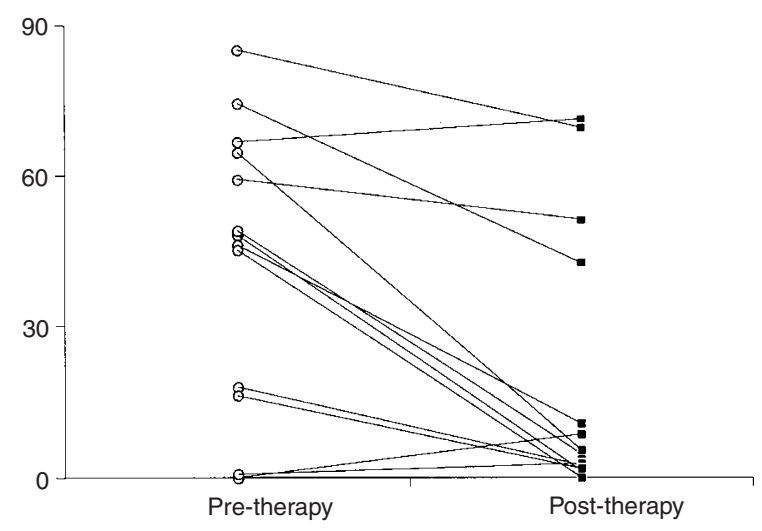

Figure 8 Comparison of topoisomerase \| expression in matched samples before and after chemotherapy $(P=0.02$, Wilcoxan signed ranks matched pairs test).

(Chinese willow) and shows antitumour activity in human solid tumours including colorectal, prostate and ovarian cancers. These drugs act by preventing the resealing of the DNA, and thus transcription is unable to continue. The greater the amount of topo I a cell has, the more cleavable complexes can be formed within it, and hence, the cell is more drug sensitive (Holden et al, 1997). It has also been shown that there is good correlation between the immunohistochemical level of topo I in tissue and catalytic activity (Coleman et al, 2000). The increased expression of topo I in tumour tissue may therefore provide a target for selective therapeutic cytotoxicity in other human cancers. This is supported by experimental evidence that Camptothecin-resistant tumour cell lines express reduced levels of topo I (Husain et al, 1994).

Topo I has been measured previously in a variety of other malignancies and normal tissues, by immunochemistry, RTPCR, enzymatic activity and Western blotting. Increased expression has been shown in ovarian epithelial carcinomas (Codegoni et al, 1998), transitional cell carcinomas of the bladder (Monnin et al, 1999), renal cell carcinomas (Gupta et al, 2000) and lung tumours (Mirski et al, 2000). Normal topo I levels were seen in the background tissue of the above studies.

Two isoforms of the topo II enzyme exist - alpha and beta. The alpha form is the more important. Its activity is highest during $\mathrm{S}$, G2 and M phases, with low activity during G1 phase. Both the monoclonal and polyclonal antibodies to topo II $\alpha$ used in this study are specific for the carboxy-terminal of the molecule and do not cross-react with topo II $\beta$. The activity of topo II $\alpha$ can be up-regulated by the inhibition of topo I (Whitacre et al, 1997). This has an important clinical relevance since, it is conceivable that topo I inhibitors could be used to up-regulate topo II $\alpha$, thus making cells more sensitive to topo II $\alpha$ inhibitors. The results supported an inverse relationship between topo I and topo II $\alpha$ (Table 2).

Many drugs inhibit topo II $\alpha$ by stabilising the topo II-DNA cleavable complex (Houlbrook et al, 1995). Some topo II $\alpha$ inhibitors are able to intercalate part of their structure between adjacent DNA bases, e.g. the anthracyclines and anthracene diones which are effectively trapped in the nucleus at a high concentration. They can therefore be administered by a single injection, and will be held in the cell until S phase when topo II activity peaks and they are able exert their effect. Other inhibitors, such as etoposide, do not intercalate and require prolonged administration to increase the chance of exposure to cells during $S$ phase. Seminomas are well known to be sensitive to etoposide (Mencel et al, 1994). Evidence suggests that the cellular level of topo II $\alpha$ determines the degree of drug toxicity (Houlbrook et al, 1995). The decreased expression of topo II $\alpha$ has been shown to be associated with resistance to chemotherapy (Koshiyama et al, 2001).

The finding of most interest was the tumour specificity of high topo I expression. Both the TM group, and the yolk sac group show universal strong expression making them potential candidates for treatment with topotecan or irinotecan. The presence of high levels of topo I in TM was unexpected. TM comprises only a small minority of primary GCT's, and these are treated by surgery followed by surveillance. However, after the administration of chemotherapy, the tumours frequently change their morphology and approximately $40 \%$ of cases show pure TM. These are routinely resected, though in cases with widespread metastases these foci may be inaccessible to surgery. Despite their quiescent nature, there is a risk of progression and presentation as late recurrences (Michael et al, 2000). Thus, if topo I has been upregulated in these foci, administration of an inhibitor may represent an adjunct or alternative to surgical removal in specific cases. Yolk sac tumour is more aggressive than TM but showed similar strong positive expression for topo I. Therefore, in those cases resistant to standard regimens, administration of a topo I inhibitor may be efficacious. Coleman et al (2000) investigated the topo I and II expression in seminomas alone. Our results for expression of topo I and II are similar to theirs ( 6 out of 20 seminomas being positive for topo I in their study and 5 out of 13 in our study). The strong cytoplasmic positivity seen in many cases of EC has been disregarded. However, it has been noted that expression of a cytoplasmic mutant variant of topo II $\alpha$ has been reported in a lung cancer cell line that was etoposide resistant (Mirski and Cole, 1995). This supports the decision to disregard all cytoplasmic staining.

The primary embryonal carcinomas were the group with the highest expression of topo II $\alpha$ ( 8 out of 12) while TM had the lowest (0 out of 10). On comparison with the seminoma group, TM had a significantly lower topo II $\alpha(P=0.019)$. The significant reduction in topo II $\alpha$ after chemotherapy in matched cases is explained by the transformation to TM from EC. The lack of a normal distribution in the post-chemotherapy cases highlights the variable response to primary chemotherapy. 
Ki-67 has been shown to be a useful marker in assesment of likelihood of relapse in metastatic germ cell tumours (Berney et al, 2001b). Comparison of Ki-67 with topo II $\alpha$ shows a good correlation, indicating that topo II $\alpha$ levels are a fair indicator of proliferating cells. Topo I is thought to be most active in cells with a high $\mathrm{S}$ phase fraction as DNA replication forks collide with the stabilised topo I-DNA complex (D’Arpa et al, 1990). However, non-replicating cells have been shown to be sensitive to topo I, possibly because of collisions with transcriptional complexes (Morris and Geller, 1996; Wu and Liu, 1997). Therefore in resistant cases, topo I inhibitors may be of great utility.

It should be recognised that upsteam and downstream variables may affect the sensitivity of the tumour to these drugs. The transport proteins Mrp2/Moat (Allen et al, 1999) and Brcp/Mxr1 (Koike et al, 1997) have been implicated in the efflux of topo I inhibitors and etoposide is a substrate for the cellular efflux protein Mdr1 (Rubin, 2000). However, clinical trials on tumours resistant to conventional chemotherapy and in cases not amenable to surgery are necessary to evaluate the response of these specific types of tumour to the camptothecins.

\section{ACKNOWLEDGEMENTS}

We would like to thank Dr S Joel for help with preparation of the paper and statistical analyses and the generous donation of the blocks from the original orchidectomy cases by Professor R Ball (Norfolk and Norwich Hospital), Dr J Leake (Basildon Hospital), Dr Y Thway (Mid-Essex Hospitals), Dr B Randall (Medway Maritime Hospital) and Dr M Turner (Wycombe Hospital).

\section{REFERENCES}

Albers P, Ganz A, Hannig E, Miersch WE, Muller SC (2000) Salvage surgery of chemorefractory germ cell tumours with elevated tumour markers. Urol 164: $381-384$

Allen JD, Brinkhuis RF, Wijnholds J, Schinkel AH (1999) The mouse Bcrp1/ mxr/abcp gene: Amplification and overexpression in cell lines selected for resistance to Topotecan, mitoxantrone, or doxorubicin. Cancer Res 59: $4237-4241$

Berney DM, Shamash J, Pieroni K, Oliver RTD (2001a) Loss of CD30 expression in metastatic embryonal carcinoma: an effect of chemotherapy?. Histopathol 39: $382-385$

Berney DM, Shamash J, Hendry WF, Arora A, Jordan S, Oliver RTD (2001b) Prediction of relapse after lymph node dissection for germ cell tumours: can salvage chemotherapy be avoided?. Br J Cancer 84: 340-343

Codegoni AM, Castagna S, Mangioni C, Scovassi AI, Broggini M, D’Incalci M (1998) DNA-topoisomerase I activity and content in epithelial ovarian cancer. Ann Oncol 9: 313-319

Coleman LW, Perkins SL, Bronstein IB, Holden JA (2000) Expression of DNA Topoisomerase I and DNA Topoisomerase II-Alpha in Testicular Seminomas. Human Pathol 31: 728 - 733

D'Arpa P, Beardmore C, Liu LF (1990) Involvement of nucleic acid synthesis in cell killing mechanisms of topoisomerase poisons. Cancer Res 50: 69196924

Einhorn LH, Williams SD, Mandelbaum I, Donohue JP (1981) Surgical resection in disseminated testicular cancer following chemotherapeutic cytoreduction. Cancer 48: $904-908$

Davidson B, Goldberg I, Lerner-Geva L, Gotlieb WH, Ben-Baruch G, Novikov I, Kopolovic J (2000) Expression of topoisomerase II and Ki-67 in cervical carcinoma-clinicopathological study using immunohistochemistry. APMIS 108: 209-215

Fizazi K, Tjulandin S, Salvioni R, Germa-Lluch JR, Bouzy J, Ragan D, Bokemeyer C, Gerl A, Flechon A, De Bono JS, Stenning S, Horwich A, Pont J, Albers P, De Giorgi U, Bower M, Bulanov A, Pizzocaro G, Kerbrat P, Aparicio J, Nichols C, Theodore C, Hartman JT, Schmoll HJ, Kaye SB, Culine S, Droz JP, Mahe C (1999) Viable malignant cells after primary chemotherapy for disseminated nonseminomatous germ cell tumours: prognostic factors and the role of postsurgery. J Clin Oncol 19: 2647-2657

Fox EP, Weathers TD, Williams SD, Loehrer PJ, Ulbright TM, Donohue JP, Einhorn LH (1993) Outcome analysis for patients with persistent nonteratomatous germ cell tumour in post chemotherapy retroperitoneal lymph node dissections. J Clin Oncol 11: 1294-1299

Gupta D, Bronstein IB, Holden JA (2000) Expression of DNA topoisomerase I in neoplasms of the kidney: correlation with histological grade, proliferation, and patient survival. Hum Pathol 31: 214-219

Holden JA, Rahn MP, Jolles CJ, Vorobyev SV, Bronstein IB (1997) Immunohistochemical detection of DNA topoisomerase I in formalin fixed, paraffin wax embedded normal tissues and in ovarian carcinomas. J Clin Pathol: Molec Pathol 50: 247-253

Hull MT, Warfel KA, Eble JN, Irons DA, Foster RS (1994) Glycogen rich clear cell adenocarcinomas arising in metastatic germ cell tumours. J Urol Pathol 2: $183-194$
Houlbrook S, Addison CM, Davies SL, Carmichael J, Stratford IJ, Harris AL, Hickson ID (1995) Relationship between expression of topoisomerase II isoforms and intrinsic sensitivity to topoisomerase II inhibitors in breast cancer cell lines. Br J Cancer 72: 1454-1461

Husain I, Mohler JL, Seigler HF, Besterman JM (1994) Elevation of topoisomerase I Messenger RNA, Protein, and Catalytic Activity in Human Tumours: Demonstration of Tumour-type Specificity and Implications for Cancer Chemotherapy. Cancer Res 54: 539-546

International Germ Cell Cancer Collaborative Group (1997) International germ cell consensus classification: A prognostic factor-based staging system for metastatic germ cell cancers. J Clin Oncol 15: 594-603

Koike K, Kawabe T, Tanaka T, Toh S, Uchiumi T, Wada M, Akiyama S, Ono M, Kuwano M (1997) A canalicular multispecific organic anion transporter (cMOAT) anstisense cDNA enhances drug sensitivity in human hepatic cancer cells. Cancer Res 57: 5475-5479

Koshiyama M, Fulii H, Kinezaki M, Morita Y, Nanno H, Yoshida M (2001) Immunohistochemical expression of topoisomerase II alpha (Topo II alpha) and multidrug resistance-associated protein (MRP), plus chemosensitivity testing, as chemotherapeutic indices of ovarian and endometrial carcinomas. Anticancer Res 21: 2925-2932

Little JS, Foster RS, Ulbright TM, Donohue JP (1994) Unusual neoplasms detected in testis cancer patients undergoing post-chemotherapy retroperitoneal lymphadenectomy. J Urol 152: 1144-1149

Loehrer Sr PJ, Gronin R, Nichols CR, Weathers T, Einhorn LH (1998) Vinblastine plus ifossfamide plus cisplatin as initial salvage therapy in recurrent germ cell tumour. J Clin Urol 16: 2500-2504

Madden KN, Champoux JJ (1992) Overexpression of human topoisomerase I in baby hamster kidney cells: hypersensitivity of clonal isolates to camptothecin. Cancer Res 52: 525-532

Mcleod HL, Douglas F, Oates M, Symonds RP, Prakash D, van der Zee AG, Kaye SB, Brown R, Keith WN (1994) Topoisomerase I and II activity in human breast, cervix, lung and colon cancer. Int J Cancer 59: 607-611

Mencel PJ, Motzer RJ, Mazumdar M (1994) Advanced Seminoma: Treatment results, survival and prognostic factors in 142 patients. J Clin Oncol 12: $120-126$

Michael H, Lucia J, Foster RS, Ulbright TM (2000) The pathology of late recurrence of testicular germ cell tumours. Am J Surg Pathol 24: 257-273

Miki T, Sawada M, Nonomura N, Kojoma Y, Okuyama A, Maeda D, Saiki S, Kotake T (1997) Antitumour effect of CPT-11, a camptothecin derivative, on human testicular tumor xenografts in nude mice. Eur Urol 31: 92-96

Mirski SEL, Cole SPC (1995) Cytoplasmic localisation of a mutant $M_{r}$ $160,000 \mathrm{II} \alpha$ is associated with the loss of putative bipartite localisation signals in a drug resistant human lung cancer cell line. Cancer Res 55: $2129-2134$

Mirski SE, Voskoglou-Nomikos T, Young LC, Deeley RG, Campling BG, Gerlach JH, Cole SP (2000) Simultaneous quantitation of topoisomerase II alpha and beta isoform mRNAs in lung tumor cells and normal and malignant lung tissue. Lab Invest 80: 787-795 
Monnin KA, Bronstein IB, Gaffney DK, Holden JA (1999) Elevations of DNA Topoisomerase I in transitional cell carcinoma of the urinary bladder: correlation with DNA topoisomerase II-alpha and p53 expression. Human Pathol 30: $384-391$

Morris EJ, Geller HM (1996) Induction of neuronal apoptosis by camptothecin, an inhibitor of DNA topoisomerase I: evidence for cell cycleindependent toxicity. J Cell Biol 134: 757-770

Morisaki K, Kuroda S, Matsumoto Y, Kunishio K, Nagao S (2000) Expression of DNA topoisomerase I, IIalpha, and IIbeta in human brain tumors. Brain Tumor Pathol 17: 7-13

Rubin EH (2000) DNA topoisomerase expression in tumours-a novel target for chemotherapy. Human Pathol 31: 631-632

Sano K, Shuhin T (1995) A study of topoisomerase activity in human testicular cancers. Anticancer Res 15: 2117-2120

Shamash J, Oliver RTD, Ong J, Raja M, Edmonds P, Gallagher CJ, Ostrowski J, LeVay J, Williams M (1999) 60\% salvage rate for germ cell tumours using sequential $\mathrm{m}-\mathrm{BOP}$, surgery and ifosfamide based chemotherapy. Annals of Oncology 10: 685-692
Tait D, Peckham MJ, Hendry WF, Goldstraw P (1984) Post-chemotherapy surgery in advanced non-seminomatous germ cell testicular tumours: the significance of histology with particular reference to differentiated (mature) teratoma. Br J Cancer 50: 601-609

Takimoto CH, Wright J, Arbuck SG (1998) Clinical applications of the camptothecins. Biochim Biophys Acta 1400: $107-119$

Wang JC (1996) DNA topoisomerases. Ann Rev Biochem 65: 635-692

Whitacre CM, Zborowska E, Gordon NH, Mackay W, Berger NA (1997) Topotecan increases topoisomerase II alpha levels and sensitivity of treatment with etoposide in schedule-dependent process. Cancer Res 15: $1425-$ 1428

Williams SD, Stablein DM, Einhorn LH, Muggia FM, Weiss RB, Donohue JP, Paulson DF, Brunner KW, Jacobs EM, Spaulding JT, DeWys WD, Crawford ED (1997) Immediate adjuvant chemotherapy versus observation with treatment at relapse in pathological stage II testicular cancer. New Engl J Med 317: $1433-1438$

Wu J, Liu LF (1997) Processing of topoisomerase I cleavable complexes into DNA damage by transcription. Nucl Acids Res 25: 4181-4186 